Microbial Ecology (2010) 60:55-68

DOI 10.1007/s00248-010-9666-x

\title{
Laboratory-Induced Endolithic Growth in Calcarenites: Biodeteriorating Potential
} Assessment

A. Z. Miller(1,2), M. A. Rogerio-Candelera(3), L. Laiz(3), J. Wierzchos(4), C. Ascaso(4), M. A. Sequeira Braga (5), M. Hernández-Mariné (6), A. Maurício(2), A. Dionísio(2), M. F. Macedo (7), C. Saiz-Jimenez(3)

(1) Departamento de Conservação e Restauro, Faculdade de Ciências e Tecnologia, Universidade Nova de Lisboa, Monte de Caparica, 2829-516 Caparica, Portugal

(2) Centro de Petrologia e Geoquímica, Instituto Superior Técnico, Av. Rovisco Pais, 1049-001 Lisbon, Portugal, e-mail: azm@fct.unl.pt

(3) Instituto de Recursos Naturales y Agrobiologia, CSIC, Av. Reina Mercedes 10, 41012 Sevilla, Spain

(4) Instituto de Recursos Naturales, Centro de Ciencias Medioambientales, CSIC, Serrano, 115 bis, 28006 Madrid, Spain

(5) Centro de Investigação Geológica, Ordenamento e Valorização de Recursos (CIG-R), Universidade do Minho, Campus de Gualtar, 4710-057 Braga, Portugal

(6) Facultat de Farmacia, Universitat de Barcelona, Av. Joan XXIII, s/n, 08028 Barcelona, Spain

M. F. Macedo

(7) Vicarte, Faculdade de Ciências e Tecnologia, Universidade Nova de Lisboa, Monte de Caparica, 2829-

516 Caparica, Portugal

\begin{abstract}
This study is aimed to assess the formation of photosynthetic biofilms on and within different natural stone materials, and to analyse their biogeophysical and biogeochemical deterioration potential. This was performed by means of artificial colonisation under laboratory conditions during 3 months. Monitoring of microbial development was performed by image analysis and biofilm biomass estimation by chlorophyll extraction technique. Microscopy investigations were carried out to study relationships between microorganisms and the mineral substrata. The model applied in this work corroborated a successful survival strategy inside endolithic microhabitat, using natural phototrophic biofilm cultivation, composed by cyanobacteria and algae, which increased intrinsic porosity by active mineral dissolution. We observed the presence of minerallike iron derivatives (e.g. maghemite) around the cells and intracellularly and the precipitation of hausmannite, suggesting manganese transformations related to the biomineralisation.
\end{abstract}

Key-words - biodeteriorating, calcarenites, endolithic growth, biomineralisation. 